\title{
Oligonucleotides Antisense to the Interleukin 1 Receptor mRNA Block the Effects of Interleukin 1 in Cultured Murine and Human Fibroblasts and in Mice
}

Ronald M. Burch* and Lawrence C. Mahan*

${ }^{*}$ Nova Pharmaceutical Corporation, Baltimore, Maryland 21224; and ${ }^{\ddagger}$ National Institute of Mental Health, Laboratory of Cell Biology, Bethesda, Maryland 20892

\begin{abstract}
Phosphodiester and phosphorothioate oligodeoxynucleotides (18 mers) were constructed antisense to sequences of the recently cloned murine and human IL-1 receptors. Murine antisense oligonucleotides inhibited IL-1-stimulated PGE $_{2}$ synthesis by murine fibroblasts in culture in a time (days) and concentration-dependent (3 $\mu \mathrm{M}-30 \mu \mathrm{M})$ fashion. Murine sense oligonucleotide and an oligonucleotide antisense to human IL-1 receptor were without effect. Moreover, murine antisense oligonucleotides did not affect tumor necrosis factor- or bradykininstimulated $\mathrm{PGE}_{2}$ synthesis by murine fibroblasts. Similarly, antisense oligonucleotides to the human, but not the murine, IL-1 receptor inhibited IL-1-stimulated PGE $_{2}$ synthesis by cultured human fibroblasts. The attenuation of the cellular response to IL-1 caused by the antisense oligonucleotides correlated with a loss in cell surface receptors for IL-1, without any change in the number of bradykinin receptors on these cells. When antisense oligonucleotides were encapsulated in liposomes, they blocked completely the appearance of newly synthesized IL-1 receptors and IL-1-stimulated PGE 2 synthesis. In mice, subcutaneous injection with an oligonucleotide antisense to the murine IL-1 receptor markedly inhibited the infiltration of neutrophils in response to subsequent injection of IL-1. These data suggest that antisense oligodeoxynucleotides may share a role in the design of antiinflammatory therapeutics. (J. Clin. Invest. 1991. 88:1190-1196.) Key words: inflammation • dermatitis $\bullet$ neutrophil infiltration
\end{abstract}

\section{Introduction}

IL-1, a cytokine released from a variety of cells in response to inflammatory insult, is implicated in the pathogenesis of several chronic inflammatory diseases, including rheumatoid arthritis (1). IL-1 elicits its effects by binding to specific cell-surface receptors on a broad spectrum of cell types. IL-1 receptors expressed by $\mathrm{T}$ lymphocytes, endothelial cells, and fibroblastlike cells (so called type I receptors) are thought to be identical, whereas IL-1 receptors on macrophages and B lymphocytes (type II receptors) are different (2-4). Recently, type I IL-1 receptors have been cloned from human and murine $T$ lymphocyte and human fibroblasts (5-7) and the amino acid sequences were found to be highly conserved between species.

Address reprint requests to Ronald M. Burch, M.D., Ph.D., Nova Pharmaceutical Corporation, 6200 Freeport Centre, Baltimore, MD 21224.

Received for publication 18 January 1991 and in revised form 16 May 1991.

The Journal of Clinical Investigation, Inc.

Volume 88, October 1991, 1190-1196
We wish to study the expression and activation of IL-1 receptors in cells and to assess the role of IL-1 in physiological and pathological processes. Evidence that $\mathrm{IL}-1$ is implicated in the pathogenesis of certain inflammatory diseases has generated great interest in developing therapeutic agents which inhibit the biological effects of this cytokine. Antisense oligodeoxynucleotides present a potential alternative therapeutic approach. Antisense oligodeoxynucleotides have been used to block translation of proteins both in cell-free translation systems and in cultured cells (8). Use of natural phosphodiestercontaining oligonucleotides $\left(\mathrm{O}^{1}\right.$-oligos) in studies using intact cells or animals is limited by their rapid metabolism by endogenous nucleases (9). However, phosphorothioate oligonucleotides (S-oligos) are more nuclease-resistant (10), making them potentially useful in vivo, even though they are taken up into cells more slowly (9). To date, however, most studies using antisense oligodeoxynucleotides have focused on the inhibition of expression of viral genes and oncogenes. To assess the capability that these agents may possess to modulate cytokinemediated responses, we have designed species-specific oligodeoxynucleotides antisense to mRNA sequences for the human and murine IL-1 receptors. We have used these agents to study aspects of cellular and species-specific targeting and their ability to attenuate IL-1 mediated responses in vitro. In addition, we have extended these findings to an in vivo model of cytokine-mediated inflammation to block neutrophil infiltration in response to local administration of IL-1 in mouse dermal tissue.

\section{Methods}

Cell culture. 3T3 fibroblasts were cultured as described in DMEM supplemented with $10 \%$ calf serum (11) to confluency in 96-well plates. Human dermal fibroblasts were obtained from Clonetics Corp., San Diego, CA, and were cultured in DMEM containing 10\% fetal bovine serum.

IL-1 binding. IL-1 binding experiments were performed as described (12). Confluent cultures in 24-well plates were washed twice with HBSS containing $20 \mathrm{mM}$ Hepes, $\mathrm{pH} 7$. To each dish was added $200 \mu \mathrm{l}$ ice-cold HBSS containing $20 \mathrm{mM}$ Hepes, $1 \mathrm{mg} / \mathrm{ml} \mathrm{BSA}$, and 50 nCi human recombinant [ $\left.{ }^{125} \mathrm{I}\right] \mathrm{IL}-1 \alpha$ (New England Nuclear, Boston, MA). For Scatchard analyses, unlabeled IL- $1 \alpha$ (Boehringer Mannheim Corp., Indianapolis, IN) was added to vary concentration. Nonspecific binding was determined in the presence of $2 \mathrm{nM}$ IL- $1 \beta$ (Boehringer Mannheim). To terminate experiments, the cultures were incubated on ice for $60 \mathrm{~min}$, then each culture was washed four times with $10 \mathrm{ml}$ ice-cold HBSS containing $1 \mathrm{mg} / \mathrm{ml}$ BSA. Cells were removed from plates using HBSS containing trypsin. Cell-associated radioactivity was determined using a gamma counter and was $\sim 3,000 \mathrm{dpm} /$ well in the absence of added unlabeled IL-1 and 100-150 dpm in the presence of 2

1. Abbreviations used in this paper: $\mathrm{h}$, human; $\mathrm{m}$, murine; $\mathrm{O}$, phosphodiester; S, phosphorothioate. 
nM unlabeled IL-1 $\beta$. $K_{d}$ and maximal binding capacity $\left(\mathrm{B}_{\max }\right)$ were determined using LIGAND (Biosoft, Milltown, NJ) (13).

Bradykinin binding. Bradykinin receptor binding to cell membranes was carried out as described (11). Cells were scraped into $100 \mathrm{vol}$ of a buffer composed of $25 \mathrm{mM} \mathrm{N}$-tris(hydroxymethyl)methyl-2-aminoethane-sulfonic acid, $0.2 \mathrm{~g} /$ liter 1,10-phenanthroline, $\mathrm{pH} 6.8$, and homogenized using a Polytron Tissumizer (Brinkmann Instruments, Inc., Westbury, NY) at setting 6 for $15 \mathrm{~s}$. The homogenate was centrifuged at $50,000 \mathrm{~g}$ for $10 \mathrm{~min}$, the supernatant discarded, and the pellet resuspended into the same buffer also containing $1 \mathrm{~g} /$ liter BSA and 0.14 $\mathrm{g} /$ liter bacitracin. To assay tubes were added $\left[{ }^{3} \mathrm{H}\right]$ bradykinin, the amount of radioactivity being varied in the tubes to vary concentration for Scatchard analysis. Nonspecific binding was determined in the presence of $10 \mu \mathrm{M}$ NPC 567, a bradykinin antagonist (11). Assays were terminated by filtration through glass fiber filters that had been soaked in $2 \mathrm{~g} /$ liter polyethyleneimine for $1 \mathrm{~h}$, and washed four times with $4 \mathrm{ml}$ of ice-cold $50 \mathrm{mM}$ Tris, $\mathrm{pH} 7.4$.

$P G E_{2}$ synthesis. $\mathrm{PGE}_{2}$ was quantitated from direct aliquots of media using a radioimmunoassay as previously described for these cells and media (11). Reagents were from Advanced Magnetics, Inc., Cambridge, MA, and control experiments demonstrated that none of the experimental agents (IL-1, tumor necrosis factor, bradykinin, or antisense oligonucleotides) affected the assay.

Liposomes. Liposomes were constructed of phosphatidylserine (14), loaded with oligonucleotides, and fused to the cells (9). Phosphatidylserine (Avanti Polar Lipids, Inc., Birmingham, AL), $5 \mathrm{mg}$ in $1 \mathrm{ml}$ chloroform, was placed into a spherical flask and, under a nitrogen atmosphere, the chloroform was removed using a rotary evaporator, leaving a film of lipid. The lipid was resuspended in $0.2 \mathrm{ml}$ EDTA buffer $(100 \mathrm{mM} \mathrm{NaCl}, 2 \mathrm{mM}$ histidine, $2 \mathrm{mM}$ Tris acid, $0.1 \mathrm{mM}$ EDTA, pH 7.4) with vigorous vortexing to form multilamellar vesicles. Then $\mathrm{CaCl}_{2}$ was added to $10 \mathrm{mM}$ to form cochleate bodies. Oligonucleotide was added and the mixtures were allowed to stand at room temperature for $1 \mathrm{~h}$. EDTA was then added to $15 \mathrm{mM}$ and the $\mathrm{pH}$ adjusted to 7 to cause liposome formation. This solution was allowed to stand for $30 \mathrm{~min}$. Liposomes were concentrated by centrifugation at 100,000 $g$ for $30 \mathrm{~min}$ at room temperature and gently washed with HBSS. For lipofusion, cells were rinsed with HBSS, then incubated in HBSS containing $2 \mathrm{mM}$ calcium and $0.1 \mathrm{mM}$ magnesium for $30 \mathrm{~min}$. Liposomes were added to a concentration of $1.25 \mathrm{mg} / \mathrm{ml}$ lipid and incubated for 30 min. To the cultures was then added a volume of polyethylene glycol $(6,000$ average molecular mass) equal to the salt solution in the well (resulting in 50\% polethylene glycol) for $1 \mathrm{~min}$, followed by addition of culture medium containing serum, and careful washing of the wells three times to remove the polyethylene glycol. In an experiment to determine the efficiency of oligonucleotide incorporation, oligonucleotide was ${ }^{32} \mathrm{P}$-endlabeled before incorporation into liposomes. After one wash $12 \%$ of radioactivity was retained in the liposome pellets. Re- peated washing demonstrated that $6-7 \%$ of radioactivity was stably retained.

Labeling neutrophils. In the experiments in mice, in vivo, the day before IL-1 was to be administered, animals received $10 \mu \mathrm{Ci}\left[{ }^{3} \mathrm{H}\right]$ thymidine i.p. to label circulating neutrophils. Using this method, $24 \mathrm{~h}$ after injection, virtually all radioactivity in the blood is contained within the DNA of neutrophils (15). Hair was shaved from the backs before the beginning of the experiment. IL- 1 was administered intradermally $1 \mathrm{~cm}$ lateral to the spine and, $4 \mathrm{~h}$ later, animals were killed by cervical dislocation. Skin was removed and $8 \mathrm{~mm}$ punch biopsies were obtained. These were dissolved in Protosol (New England Nuclear) overnight, then radioactivity was determined by liquid scintillation counting. Background radioactivity was determined by taking biopsies from areas that had been injected intradermally with saline not containing IL-1. Each animal served as its own control in that murine antisense oligonucleotides were injected on one side of the midline whereas on the other side, injections contained the human antisense oligonucleotide, which is inactive in mouse cells in culture (see $R \boldsymbol{e}$ sults).

Oligonucleotides. Oligodeoxynucleotides were synthesized (Synthecell Corp., Rockville, MD) complementary to unique species-specific coding regions of mRNA for murine and human IL-1 receptors. These included 18-base regions at the initiation codon (mO-oligo-1,5'CACTTTCATATTCTCCAT, complementary to bases -57 to -40 of the murine sequence [6], and $\mathrm{mS}$-oligo-1, the analogous phosphorothioate analog; hO-oligo-1,5'-TCTGAGTAACACTTTCAT, complementary to bases -51 to -34 of the human IL-1 receptor sequence [5], and hS-oligo-1, the analogous phosphorothioate analogue), an internal open reading frame site (mS-oligo-2, a phosphorothioate analogue of sequence 5'-GAGACAAATGAGCCCCAG, complementary to bases -36 to -19 of the murine sequence), and a region immediately $5^{\prime}$ to the termination codon (mS-oligo-3, a phosphorothioate analogue of sequence 5'-GCCGAGTGGTAAGTGTGT complementary to bases 1654-1671 of the murine sequence). Two sense phosphorothioate oligonucleotides were used, equivalent to mS-oligo-1,5'-ATGGAGAATATGAAAGTG, and hS-oligo-1,5'-ATGAAAGTGTTACTCAGA as controls.

\section{Results}

Time course for inhibition of IL-1-stimulated $P G E_{2}$ synthesis by antisense oligonucleotides. In initial experiments, both $\mathrm{mO}-$ oligo-1 and mS-oligo-1, $10 \mu \mathrm{M}$, inhibited IL-1-stimulated $\mathrm{PGE}_{2}$ synthesis in cultures of murine fibroblasts grown in media with serum that had been heat-inactivated to denature nucleases (16) (Fig. 1 A). The O-oligo was more acute in effect,
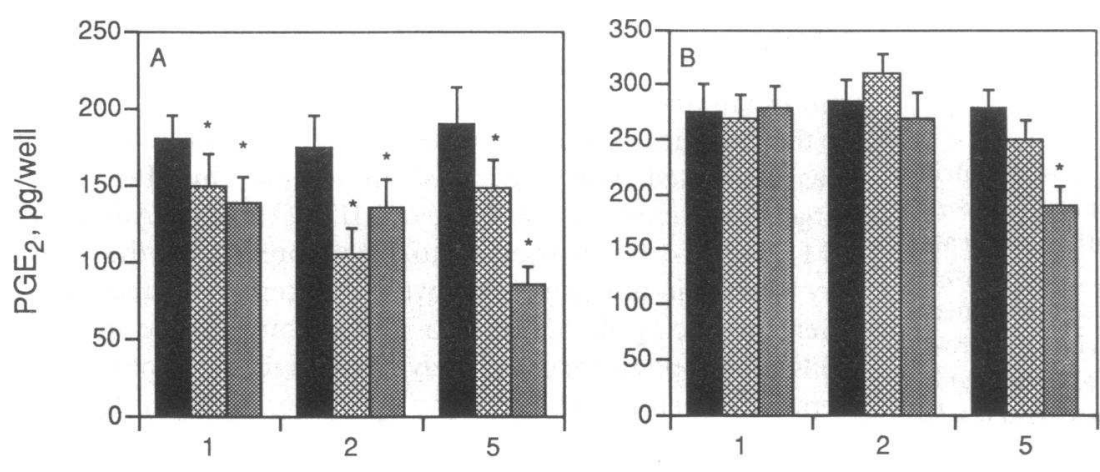

Days incubation
Figure 1. Time course for inhibition of IL-1-stimulated $\mathrm{PGE}_{2}$ synthesis by antisense oligonucleotides in murine fibroblasts. 3T3 fibroblasts were cultured to confluency, then $10 \mu \mathrm{M}$ mO-oligo-1 or mS-oligo-1 was added. After incubation for the indicated times, the media were replaced and IL$1 \alpha, 100 \mathrm{U} / \mathrm{ml}$ was added, and cultures were incubated for $4 \mathrm{~h}$. Then media were collected and assayed for $\mathrm{PGE}_{2}$. IL-1 stimulation in control cultures ( filled bars), and in cultures incubated with mO-oligo-1 (crossed bars) or mS-oligo-1 (stippled bars). Basal synthesis was $42-56 \mathrm{pg} /$ well. ${ }^{*} P$ $<0.05$ compared to no oligonucleotide by Student's $t$ test for paired data. $(A)$ Cultures contained $10 \%$ heat-inactivated calf serum. $(B)$ Cultures contained $10 \%$ calf serum that had not been heat inactivated. Data are mean \pm SEM for triplicate cultures. 
while the effect of the S-oligo became more pronounced over a longer period of time. In culture media containing serum that had not been heat-inactivated the O-oligo was without effect, while the S-oligo was still capable of some inhibition of the biological effect of IL-1 (Fig. $1 \mathrm{~B}$ ).

Concentration response for inhibition of $I L-1-$ stimulated $P G E_{2}$ synthesis by antisense oligonucleotides. To compare the relative potencies of several antisense oligonucleotides directed to different regions of mRNA for IL-1 receptors, murine fibroblasts were incubated with various concentrations of S-oligos for $48 \mathrm{~h}$. mS-oligo-1, a sequence antisense to the initiation site, was more potent at inhibiting IL-1-stimulated $\mathrm{PGE}_{2}$ synthesis than mS-oligo-2, which is antisense to a sequence immediately downstream from mS-oligo-1 (Fig. $2 A$ ). At a concentration as low as $3 \mu \mathrm{M}$, mS-oligo-1 significantly inhibited IL-1-stimulated $\mathrm{PGE}_{2}$ synthesis. $\mathrm{mS}$-oligo-3, which is antisense to a sequence near the termination codon of the IL-1 receptor mRNA, was without effect on IL-1-stimulated $\mathrm{PGE}_{2}$ synthesis.

Inhibition of IL-1 receptor-mediated $\mathrm{PGE}_{2}$ synthesis by the antisense oligonucleotides was selective. While $\mathrm{mS}$-oligo-1 blocked IL-1-stimulated $\mathrm{PGE}_{2}$ synthesis, it was without effect on tumor necrosis factor- or bradykinin-induced $\mathrm{PGE}_{2}$ synthesis. Tumor necrosis factor (Genzyme Corp., Cambridge, MA), $10 \mathrm{nM}$, stimulated $\mathrm{PGE}_{2}$ synthesis from $45 \pm 6$ to $216 \pm 15 \mathrm{pg} /$ well in $4 \mathrm{~h}$ in control cultures, and from $38 \pm 10$ to $210 \pm 18$ $\mathrm{pg} /$ well in cultures that had been incubated with $30 \mu \mathrm{M} \mathrm{mS}$ oligo-1 for $2 \mathrm{~d}$. Bradykinin, $1 \mu \mathrm{M}$, stimulated $\mathrm{PGE}_{2}$ synthesis from $12 \pm 3$ to $44 \pm 6 \mathrm{pg} /$ well in $5 \mathrm{~min}$, and from $15 \pm 5$ to $47 \pm 5$ $\mathrm{pg} /$ well in cultures incubated with $30 \mu \mathrm{M} \mathrm{mS}$-oligo- 1 for $2 \mathrm{~d}$. In addition, neither hS-oligo-1, an antisense oligonucleotide directed to the initiation codon region of the human IL-1 receptor, nor the sense oligonucleotide complementary to $\mathrm{mS}$-oligo1 , had any effect on IL-1-stimulated $\mathrm{PGE}_{2}$ synthesis in murine fibroblasts (Fig. 2 and data not shown). Analogous to murine fibroblasts, the response of human dermal fibroblasts to IL-1 was inhibited by incubation with hS-oligo-1, but not by $\mathrm{mS}$ oligo-1 or the sense oligonucleotide complementary to hSoligo-1 (Fig. $2 B$ and data not shown).

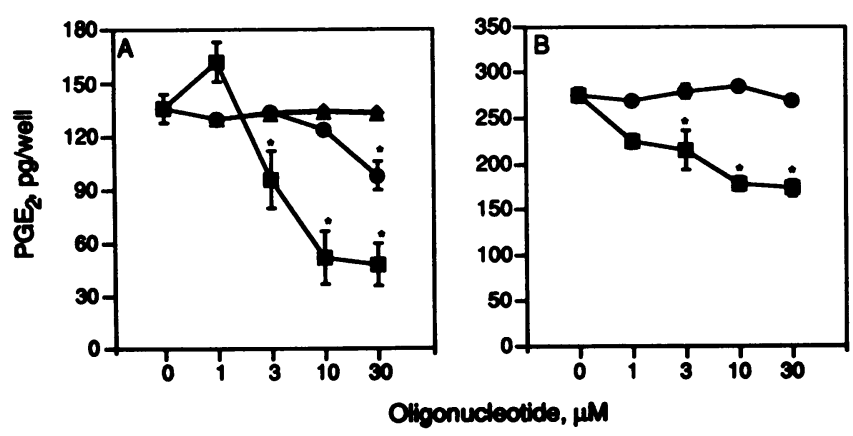

Figure 2. Concentration response for inhibition of IL-1-stimulated $\mathrm{PGE}_{2}$ synthesis by oligodeoxynucleotides in murine and human dermal fibroblasts. Confluent cultures were incubated with the indicated S-oligos for $48 \mathrm{~h}$, then media were replaced and IL-1, $100 \mathrm{U} / \mathrm{ml}$, was added and cultures were incubated for $4 \mathrm{~h}$ before collection of media for assay of $\mathrm{PGE}_{2}$. (A) IL-1-stimulated $\mathrm{PGE}_{2}$ synthesis in $3 \mathrm{~T} 3$ fibroblasts in the presence of $\mathrm{mS}$-oligo-1 ( $\bullet$, $\mathrm{mS}$-oligo-2 (๑), $\mathrm{mS}$-oligo-3 $(\triangle)$, or hS-oligo-1 (४). Data are mean \pm SEM for triplicate cultures. $(B)$ IL-1-stimulated $\mathrm{PGE}_{2}$ synthesis in human dermal fibroblasts in the presence of hS-oligo-1 ( $\bullet$ ) or $\mathrm{mS}$-oligo-1 (๑). Data are mean \pm SEM for triplicate cultures. ${ }^{*} P<0.05$ compared to no oligonucleotide.
Antisense oligonucleotides reduce expression of IL-1 surface receptors. The attenuation of the cellular response to IL-1 caused by the antisense oligonucleotides correlated with a loss in cell surface receptors for IL-1 in murine fibroblasts. The number and affinity of IL-1 receptors were assessed in murine fibroblasts treated with $\mathrm{mS}$-oligo-1 for $48 \mathrm{~h}$ and compared to control fibroblasts. Scatchard analysis demonstrated that the affinity of IL-1 receptors was not altered by treatment with $\mathrm{mS}$-oligo-1, but receptor number was decreased to only $55 \%$ of control (Fig. 3). In contrast, mS-oligo-1 did not affect the number of receptors for bradykinin (Fig. 4), demonstrating that the effects of the antisense oligonucleotides were specific to the IL-1 receptor and not due to a cytotoxic effect on the cells.

Encapsulation in liposomes enhances the activity of $S$-oligos. The time course over which antisense oligonucleotides inhibited cellular responsiveness to IL-1 may have reflected slow turnover of receptors at the cell surface or slow uptake of the oligonucleotides, especially the S-oligos, into cells. To gain insight into which mechanism was predominant, we enhanced delivery of hS-oligo-1 by liposome encapsulation and fusion to human dermal fibroblasts under conditions of steady-state (basal) turnover of receptors and in cells undergoing rapid turnover of their IL-1 receptors. Thus, in the latter case, we treated human fibroblasts for $18 \mathrm{~h}$ with $1 \mathrm{nM}$ IL-1 to downregulate IL-1 receptors and IL-1 was then removed to allow recovery of receptors via new receptor synthesis (17-19). We included hSoligo-1 free in solution or encapsulated in liposomes, to determine whether liposomal delivery of the oligonucleotide into cells could block recovery of responsiveness to IL-1. In cells that had not been exposed to IL-1 to initiate receptor turnover, these short-term incubations of cultures with either free hSoligo-1 or mS-oligo-1 did not affect response to IL-1 as would be predicted from the data in Fig. 1. Of interest, exposure of cells during steady-state turnover of IL-1 receptors to liposome-encapsulated hS-oligo-1 was also without short-term effect on response to IL-1 (Table I). If, however, cells were exposed to liposome-encapsulated hS-oligo-1 during a period of new receptor expression, complete blockade of the ability of cells to recover responsiveness to activation of IL-1 receptors was observed. No effect of hS-oligo-1 free in solution was seen under these conditions.

Parallel with the studies of recovery of IL-1 responsiveness in the downregulated fibroblasts, we performed IL-1 receptor binding experiments to assure that receptor number correlated with biological responsiveness. Receptor binding studies were carried out as in Fig. 3, but monitoring only specific binding as described (18). Thus, radiolabeled IL-1 (10 nCi) was added to each well in the absence or presence of $2 \mathrm{nM}$ unlabeled IL-1 to account for nonspecific binding. Total specific binding was defined as binding in the presence of radiolabeled IL-1 alone minus binding in the presence of $2 \mathrm{nM}$ unlabeled IL-1. Similar to the biological response, incubation of cells with IL-1 for $18 \mathrm{~h}$ was associated with a decrease in receptor number which largely recovered $4 \mathrm{~h}$ after removing IL-1 (Table II). Adding 30 $\mu \mathrm{M}$ hS-oligo- 1 free in solution to the cultures during the recovery period did not prevent recovery of receptor number, however, enhancing the delivery of the oligonucleotide into the cells using liposomes completely blocked recovery of IL-1 receptors: in cells to which empty liposomes had been fused at the beginning of recovery time, specific binding returned to control levels, while in cells that had been fused with liposomes containing a final concentration of $30 \mu \mathrm{M}$ hS-oligo-1, specific 


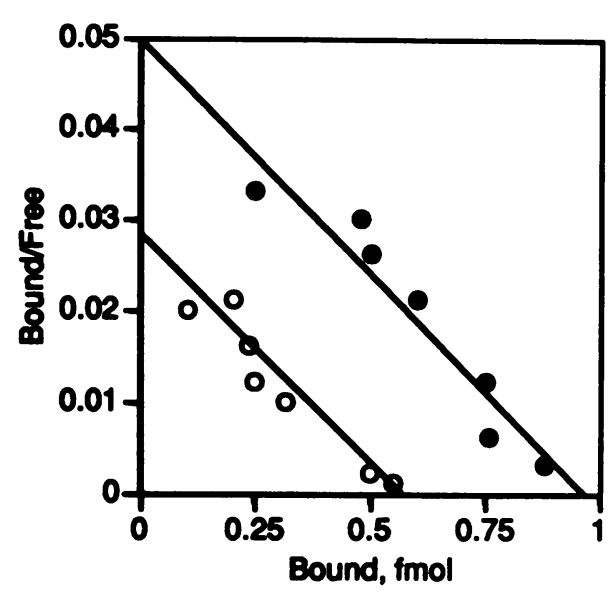

Figure 3. Scatchard analysis of binding of human recombinant IL-1 $\alpha$ to cell surface receptors on $3 \mathrm{~T} 3$ fibroblasts. Illustrated are results from a single experiment. $K_{\mathrm{d}}$ and $\mathrm{B}_{\max }$ (from three separate experiments) were $145 \pm 26 \mathrm{pM}$ and $1.01 \pm 0.09 \mathrm{fmol}(2,678$ receptors/cell $)$ in control cultures ( $\bullet$ ) and $132 \pm 30 \mathrm{pM}$ and $0.56 \pm 0.14 \mathrm{fmol}$ in cultures incubated with $\mathrm{mS}$-oligo-1 ( $30 \mu \mathrm{M}$ for $2 \mathrm{~d}$ ) (0). In cultures incubated with hS-oligo-1, $30 \mu \mathrm{M}$, for $2 \mathrm{~d}, K_{\mathrm{d}}$ was $165 \pm 20 \mathrm{pM}$ and $\mathrm{B}_{\max }$ was $1.06 \pm 0.19 \mathrm{fmol}$.

binding was unchanged from downregulated levels. Thus the half-life of IL-1 receptors at the cell surface play a major role in the biological efficacy of antisense oligonucleotides although attenuation of expression of receptors is considerably augmented using liposome delivery under conditions of new receptor synthesis.

Antisense oligonucleotides block IL-1 effects in mice. Additional experiments were performed to determine whether the effects of the antisense oligonucleotides on IL- 1 receptor function in cultured cells could be extended in vivo to an animal model of cytokine-mediated inflammatory response. Subcutaneous injection of IL-1 in mice causes neutrophil infiltration at the site of injection $(20,21)$. Mice were injected subcutaneously with either $\mathrm{mS}$-oligo-1 or hS-oligo-1 at 24-h intervals over a period of $3 \mathrm{~d}$. $24 \mathrm{~h}$ before subsequent subcutaneous

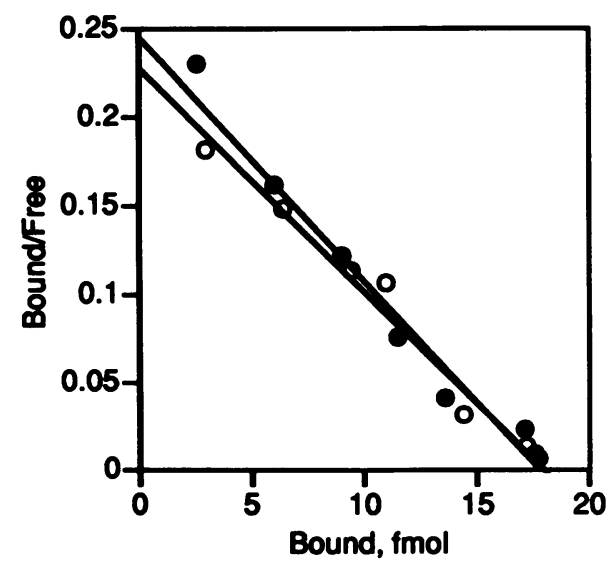

Figure 4. Scatchard analysis of binding of bradykinin to membranes from 3T3 fibroblasts. Illustrated are the results from a single experiment. In membranes from control cultures $(\bullet)(n=3)$ there were $2,960 \pm 410$ receptors per cell with $K_{\mathrm{d}}$ of $112 \pm 16 \mathrm{pM}$ compared to $3,045 \pm 360$ receptors per cell with $K_{\mathrm{d}}$ of $125 \pm 20 \mathrm{pM}$ in membranes from cells incubated with $30 \mu \mathrm{M}$ mS-oligo-1 (o) for $2 \mathrm{~d}$.
Table I. Liposome Delivery of S-oligos to Human Dermal Fibroblasts IL-1-induced PGE $E_{2}$ Synthesis

\begin{tabular}{cc}
\hline Condition & PGE $_{2}$ \\
\hline & $p g /$ well
\end{tabular}

Basal receptor turnover

Basal $\quad 46 \pm 10$

IL-1 $18 \mathrm{~h}$, wash $8 \mathrm{~h} \quad 52 \pm 12$

no IL-1, wash with media $8 \mathrm{~h}, \mathrm{IL}-14 \mathrm{~h} \quad 744 \pm 22$

no IL-1, incubate $8 \mathrm{~h}$ with liposome hS-oligo-1, IL-1 $4 \mathrm{~h} \quad 695 \pm 48$

no IL-1, incubate $8 \mathrm{~h}$ with liposome mS-oligo-1, IL-1 $4 \mathrm{~h} \quad \mathbf{7 1 8} \pm 42$

Receptor downregulation/accelerated receptor reappearance

IL-1 $18 \mathrm{~h}$, wash $8 \mathrm{~h}$, IL-1 $4 \mathrm{~h}$

$398 \pm 25$

IL-1 $18 \mathrm{~h}$, wash $8 \mathrm{~h}$ with hS-oligo-1, IL-1 $4 \mathrm{~h} \quad 385 \pm 32$

IL-1 $18 \mathrm{~h}$, wash $8 \mathrm{~h}$ with mS-oligo-1, IL-1 $4 \mathrm{~h} \quad 376 \pm 36$

IL-1 $18 \mathrm{~h}$, wash $8 \mathrm{~h}$ with liposome hS-oligo-1 68 15

IL-1 $18 \mathrm{~h}$, wash $8 \mathrm{~h}$ with liposome mS-oligo-1, IL-1 $4 \mathrm{~h} \quad 285 \pm 40$

IL-1 $18 \mathrm{~h}$, wash $8 \mathrm{~h}$ with liposome hS-oligo-1, IL-1 $4 \mathrm{~h} \quad 74 \pm 25$

Data are mean \pm SEM of triplicate wells for each condition. Human dermal fibroblasts grown to confluency in serum-free media (Clonetics Corp.) in 96-well plates were exposed to human recombinant IL-1 (Boehringer Mannheim), $100 \mathrm{U} / \mathrm{ml}$, for $18 \mathrm{~h}$. The cultures were then washed four times with media to remove IL- 1 and incubated in IL1-free media for $8 \mathrm{~h}$. The media contained oligonucleotides, $30 \mu \mathrm{M}$, or liposomes loaded with oligonucleotides, $30 \mu \mathrm{M}$ final concentration in the culture wells, as indicated. At the end of the 8-h incubation period cultures were washed twice and media replaced with culture media containing IL-1 $(100 \mathrm{U} / \mathrm{ml})$. Incubation was for $4 \mathrm{~h}$, after which supernatants were collected to quantitate $\mathrm{PGE}_{2}$. The media in control cultures were changed at the same intervals as the experimental cultures.

injection of IL-1 to initiate neutrophil infiltration, the circulating neutrophil population was labeled with $\left[{ }^{3} \mathrm{H}\right]$ thymidine (15). Significant reduction of IL-1-stimulated neutrophil infiltration was observed as early as $48 \mathrm{~h}$, or two injections of mSoligo-1. After three daily injections of mS-oligo-1, IL-1-stimulated neutrophil infiltration was markedly reduced (Table III). In all these experiments, control injections, vehicle or hS-oligo1 , were without effect. Lack of effect of hS-oligo-1, which contains a 5-base mismatch to the murine sequence, correlated well with results obtained in vitro described above.

\section{Discussion}

Antisense oligodeoxynucleotides are an attractive potential method to inhibit expression of cell-surface receptors and attenuate cellular responsiveness. Few reports exist that use synthetic oligomers to target receptors in cells. Synthetic antisense RNA to the subunit of the nicotinic acetylcholine receptor inhibited the expression of receptor-activated currents when coinjected with Torpedo mRNA in Xenopus oocytes (22). Antisense RNA truncated to cover more 5 ' sequences, however, was less effective than full-length RNA. A single oligodeoxynucleotide directed to $5^{\prime}$ sequences also inhibited expression of receptors when it was premixed with Torpedo mRNA and coinjected into oocytes. A more recent study found that antisense oligodeoxy-nucleotides directed against the $\zeta$ - and $\beta$-chains of the 
Table II. Liposome Delivery of S-oligos to Human Dermal Fibroblasts: IL-1 Receptor Expression

\begin{tabular}{cc}
\hline Condition & $\begin{array}{c}\text { Specific } \\
\text { Binding of } \\
{[125]-\text { IL-1 }}\end{array}$ \\
\hline$d p m / w e l l$
\end{tabular}

Basal receptor turnover

Basal

$657 \pm 62$

Receptor downregulation/acclerated receptor reappearance

IL-1 $18 \mathrm{~h}$, wash

$245 \pm 30$

IL-1 $18 \mathrm{~h}$, wash, $4 \mathrm{~h}$ recovery

$562 \pm 46$

IL-1 $18 \mathrm{~h}$, wash, $4 \mathrm{~h}$ recovery with hS-oligo- 1

$585 \pm 60$

IL-1 $18 \mathrm{~h}$, wash, $4 \mathrm{~h}$ recovery with empty liposome $\quad 560 \pm 38$

IL-1 $18 \mathrm{~h}$, wash, $4 \mathrm{~h}$ recovery with liposome hS-oligo-1 $205 \pm 16$

Data are mean \pm SEM of triplicate wells for each condition. Human dermal fibroblasts grown to confluency in serum-free media in 96well plates were exposed to $\mathrm{IL}-1,100 \mathrm{U} / \mathrm{ml}$, for $18 \mathrm{~h}$. The cultures were then washed four times with media to remove IL-1 and incubated in IL-1-free media for $4 \mathrm{~h}$. Binding was performed at the times indicated.

murine $\mathrm{T}$ cell receptor were effective in suppression of recovery of receptor-mediated function in $\mathrm{T}$ cell hybridomas that had been trypsinized to remove existing surface receptors (23).

Since IL-1 receptor-mediated responses are implicated in the pathogenesis of certain inflammatory diseases, we wished to study the effects of antisense oligodeoxynucleotides on the expression and functional activation of IL-1 receptors in cells under conditions more suitable to assess their potential for antiinflammatory action both in vitro and in vivo.

We have demonstrated that oligodeoxynucleotides antisense to the IL-1 receptor block the expression of IL-1 receptors and the biological effects of IL-1 on cultured cells. The degree to which antisense oligonucleotides inhibited IL-1 stimulated $\mathrm{PGE}_{2}$ synthesis in cultured fibroblasts varied with several factors. O-oligos, which are sensitive to degradation by nucleases, were inactive in serum-containing medium. In serum, which

Table III. mS-oligo-1 Inhibits IL-1-induced Neutrophil Infiltration in Mice

\begin{tabular}{llll}
\hline \multicolumn{1}{c}{ Condition } & \multicolumn{1}{c}{ Vehicle } & mS-oligo-1 & \multicolumn{1}{c}{ hS-oligo-1 } \\
\hline & & $l^{3} H J T d r, d p m$ & \\
One injection & $4658 \pm 1135$ & $4425 \pm 1238$ & $4534 \pm 1286$ \\
Two injections & $5082 \pm 720$ & $3512 \pm 410^{*}$ & $4825 \pm 602$ \\
Three injections & $5145 \pm 918$ & $3242 \pm 484^{\ddagger}$ & $4795 \pm 1486$
\end{tabular}

* $P=0.079,{ }^{\ddagger} P=0.017$, compared to vehicle, using Student's $t$ test for unpaired observations. Mice received subcutaneous injections of hS-oligo-1 or mS-oligo-1,3 $\mathrm{nmol}(25 \mu \mathrm{l})$, or saline, daily into the same sites for one, two, or three injections. The day before IL-1 was to be administered, animals received $\left[{ }^{3} \mathrm{H}\right]$ thymidine i.p. to label circulating neutrophils (see Methods). Recombinant human IL-1 $\alpha, 1,000 \mathrm{U}$, was injected into each site. After $4 \mathrm{~h}$, animals were killed and punch biopsies were taken. Data are mean \pm SEM from eight animals. Radioactivity $(<1,000 \mathrm{dpm})$ in punch biopsies from sites injected with saline alone and not treated with IL-1 have been subtracted from each point. had been heated to inactivate nucleases, the effect of O-oligos was comparable to nuclease-resistant S-oligos with two distinctions: while the inhibition of IL-1 responsiveness occurred more rapidly, it was also more transient. Our results are consistent with the observations that the specific transport of O-oligos across cell membranes occurs rapidly, in contrast to S-oligos which may have greater affinity for the transporter and are released more slowly into the cell interior (11). Whether the more transient inhibition observed with O-oligos was the consequence of an induction of nuclease activity remains to be determined.

Size is an important consideration in the design of antisense oligonucleotides. In subcellular preparations, it has been found that longer antisense oligonucleotides are more effective than shorter ones, presumably because binding is more thermodynamically favorable between longer complementary strands $(8$, 24). In studies using intact cells this phenomenon is far less apparent due to the inefficient transport of long oligodeoxynucleotides into cells $(22,25)$. We chose 18 mers since this size should yield absolute theoretical specificity for a single mRNA (26) while being still short enough to be transported into cells.

In addition to length, target sequences of antisense oligonucleotides play an important role in their biological efficacy. In general, antisense oligonucleotides directed to $5^{\prime}$ regions of eucaryotic mRNA, particularly near the initiation codon sequences, are more effective than those directed to more $3^{\prime}$ regions $(8,24)$. While in general agreement, our studies have extended these findings to show that even closely adjacent target sequences yield antisense oligonucleotides with strikingly different potencies. The most inhibitory murine S-oligo (mSoligo-1; $\mathrm{IC}_{50} 3 \mu \mathrm{M}$ ), directed to the initiation codon, was 10fold more potent than mS-oligo-2, directed some 20 bases downstream. The low micromolar potency observed in murine fibroblasts agrees well with that observed for S-oligos in a number of studies (8). Moreover, strict species specificity of inhibition was observed even though base mismatches varied from only two to five bases between murine and human IL-1 receptor sequences. Whether the inhibitory effects of antisense oligonucleotides are attributable to the degradation of mRNA by an RNase H-like activity in cells (27) or to translational arrest (28) it seems likely that local secondary structure of mRNAs plays a critical role in the biological efficacy of these agents.

In resting human dermal fibroblasts the antisense oligonucleotide only poorly inhibited IL-1 receptor expression after 48 $\mathrm{h}$ incubation. However, delivery of antisense oligonucleotides by encapsulation in liposomes and fusion to cells markedly increases their inhibitory potential, to essentially $100 \%$. In our studies, however, we found this only to be true under conditions where new receptor synthesis predominantly accounted for cellular responsiveness. Thus protein turnover plays an important role in the consideration of the use antisense agents in the inhibition of gene expression. The results obtained in the downregulation study with human dermal fibroblasts are consistent with an 11-h half-life for IL-1 receptors determined using IL-1 binding in cycloheximide-treated T lymphocytes (19).

Evidence that IL-1 plays a major role in the mediation of many chronic inflammatory diseases, including rheumatoid arthritis (1), has generated great interest in developing agents which inhibit the biological effects of this cytokine. Approaches being explored include drugs that block secretion of IL-1 from inflammatory cells (29-31), use of a soluble, recombinant extracellular binding domain of the IL-1 receptor to bind and 
deplete circulating cytokine (32), and competitive antagonism of the IL-1 receptor (33-35). Several proteins that compete with IL-1 for its receptor have been cloned $(34,35)$; at least one is being investigated as a potential therapeutic agent.

Antisense oligonucleotides present an attractive therapeutic approach predominantly due to their nonpeptidic nature and potential to be absolutely specific. Because the effect of IL-1 in skin is highly localized to the site of injection this was an attractive model in which to test the ability of antisense oligonucleotides to inhibit IL-1 receptor-mediated responses. Of great interest, therefore, was the observation that antisense oligodeoxynucleotides directed against IL-1 receptors blocked IL-1 stimulated neutrophil infiltration in vivo, one of a number of cellular responses in the complex cytokine-mediated inflammatory cascade in mouse dermal tissue. Injection of IL-1 into skin is associated within a few hours with infiltration of neutrophils into the site $(20,21)$ without edema $(21)$. This effect of IL-1 is a consequence of the activation of type I IL-1 receptors on endothelial cells and subsequent increase in the number of adhesion molecules expressed by these cells $(21,36,37)$. It is equally likely that activation of IL-1 receptors increases synthesis of chemotactic eicosanoids by connective tissue cells. These cells would be a primary target of the murine antisense oligonucleotides employed in our studies. It is unlikely that IL-1 receptors on neutrophils would have been affected as these cells are thought to exclusively express type II IL-1 receptors which have been recently demonstrated by cloning to share only $\sim 28 \%$ amino acid homology to the type I receptor (38). In addition, it is unlikely that intradermal antisense oligonucleotide would have significant access to neutrophils in the blood. While future studies are underway to identify the cell types in mouse dermal tissue that were targets of antisense oligonucleotides to the IL-1 receptor, this is the first report of the successful application of these agents in vivo in a system with potential therapeutic application.

Many hurdles remain, however, before the therapeutic potential of antisense oligonucleotides can be reduced to practice. Present synthetic methodologies are expensive and limited data exist on the in vivo pharmacokinetics and bioavailability of these molecules (39). Speculating that the dose-response data presented in these studies can be translated to an adult human, and, assuming that the volume of distribution of an $\mathrm{S}$-oligo is equal to plasma volume, then a single dose of $50 \mathrm{mg}$ of hS-oligo-1 should be sufficient to reach an effective plasma concentration, thereby making antisense oligonucleotides comparable to many other classes of therapeutic agents. Of course, use of specialized delivery vehicles, such as targeted liposomes, may significantly reduce the required dose and potentially enhance biological effectiveness.

\section{References}

1. Dinarello, C. A. 1989. Interleukin-1 and its biologically related cytokines. Adv. Immunol. 44:153-206.

2. Bomsztyk, K., J. E. Sims, T. H. Stanton, J. Slack, C. J. McMahan, M. A. Valentine, and S. K. Dower. 1989. Evidence for different interleukin 1 receptors in murine B- and T-cell lines. Proc. Natl. Acad. Sci. USA. 86:8034-8038.

3. Chizzonite, R., T. Truitt, P. L. Kilian, A. S. Stern, P. Nunes, K. P. Parker, K. L. Kaffka, A. O. Chua, D. K. Lugg, and U. Gubler. 1989. Two high-affinity interleukin 1 receptors represent separate gene products. Proc. Natl. Acad. Sci. USA. 86:8029-8033.

4. Scapigliati, G., P. Shiara, M. Bartalini, A. Tagliabue, and D. Boraschi. 1989. Differential binding of IL-1 a and IL-1b to receptors on B and T cells. FEBS (Fed. Eur. Biochem. Soc.) Lett. 243:394-398.
5. Sims, J. E., R. B. Acres, C. E. Grubin, C. J. McMahan, J. M. Wignall, C. J. March, and S. K. Dower. 1989. Cloning the interleukin 1 receptor from human T cells. Proc. Natl. Acad. Sci. USA. 86:8946-8950.

6. Sims, J. E., C. J. March, D. Cosman, M. B. Widmer, H. R. MacDonald, C. J. McMahan, C. E. Grubin, J. M. Wignall, J. L. Jackson, S. M. Call, et al. 1988. cDNA expression cloning of the IL-1 receptor, a member of the immunoglobulin superfamily. Science (Wash. DC). 241:585-589.

7. Chua, A. O., and U. Gubler. 1989. Sequence of the cDNA for the human fibroblast type interleukin-1 receptor. Nucleic Acids Res. 17:10114.

8. van der Krol, A. R., J. N. M. Mol, and A. R. Stuitje. 1988. Modulation of eukaryotic gene expression by complementary RNA or DNA sequences. Biotechniques. 6:958-976.

9. Loke, S. L. 1988. Delivery of c-myc antisense phosphorothioate oligodeoxynucleotides to hematopoietic cells in culture by liposome fusion: specific reduction in c-myc protein expression correlates with inhibition of cell growth and DNA synthesis. Curr. Top. Microbiol. Immunol. 141:282-289.

10. Stein, C. A., C. Subasinghe, K. Shinozuka, and J. S. Cohen. 1988. Physicochemical properties of phosphorothioate oligodeoxynucleotides. Nucleic Acids Res. 16:3209-3221.

11. Burch, R. M., J. R. Connor, and J. Axelrod. 1988. Interleukin 1 amplifies receptor-mediated activation of phospholipase A2 in 3 T3 fibroblasts. Proc. Natl. Acad. Sci. USA. 85:6306-6309.

12. Tiffany, C. L., S. Hoefler, H. W. Moser, and R. M. Burch. 1991. Arachidonic acid metabolism in fibroblasts from patients with peroxisomal diseases: response to interleukin 1. Biochim. Biophys. Acta. 1096:41-46.

13. Munson, P. J., and D. Rodbard. 1980. LIGAND: a versatile computerized approach for the characterization of ligand binding systems. Anal. Biochem. 107:220-239.

14. Papahadjopoulos, D., W. J. Vail, K. Jacobson, and G. Poste. 1975. Cochleate lipid cylinders: formation by fusion of unilamellar lipid vesicles. Biochim. Biophys. Acta. 394:483-490.

15. Young, J. M., D. A. Spires, C. J. Bedford, B. Wagner, S. J. Ballaron, and L. M. DeYoung. 1984. Role of prostanoids in phorbol tetradecanoyl, acetate-induced ear edema in the mouse ear. J. Invest. Dermatol. 82:367-372.

16. Krieg, A. M., W. C. Gause, M. F. Gourley, and A. D. Steinberg. 1989. A role for endogenous retroviral sequences in the regulation of lymphocyte activation. J. Immunol. 143:2448-2451.

17. Matsushima, K., J. Yodoi, Y. Tagaya, and J. J. Oppenheim. 1986. Downregulation of interleukin 1 (IL 1 ) receptor expression by IL 1 and fate of internalized ${ }^{125} \mathrm{I}$-labeled IL $1 \beta$ in a human large granular lymphocyte cell line. J. Immunol. 137:3183-3188.

18. Akahoshi, T., J. J. Oppenheim, and K. Matsushima. 1988. Interleukin 1 stimulates its own receptor expression on human fibroblasts through the endogenous production of prostaglandin(s). J. Clin. Invest. 82:1219-1224.

19. Mizel, S. B., P. L. Kilian, J. C. Lewis, K. A. Paganelli, and R. A. Chizzonite. 1987. The interelukin 1 receptor. Dynamics of interleukin 1 binding and internalization in T cells and fibroblasts. J. Immunol. 138:2906-2912.

20. Dunn, C. J., M. M. Hardee, and N. D. Staite. 1989. Acute and chronic inflammatory response to local administration of recombinant IL- $1 \alpha$, IL-1 $\beta$, TNF $\alpha$, and Ifn $\gamma$ in mice. Agents Actions. 27:290-292.

21. Rampart, M., and T. J. Williams. 1988. Evidence that neutrophil accumulation induced by interleukin-1 requires both local protein biosynthesis and neutrophil CD18 antigen expressin in vivo. Br. J. Pharmacol. 94:1143-1148.

22. Sumikawa, K., and R. Miledi. 1988. Repression of nicotinic acetylcholine receptor expression by antisense RNAs and an oligonucleotide. Proc. Natl. Acad. Sci. USA. 85:1302-1306.

23. Zheng, H. B. M. Sahai, P. Kilgannon, A. Fotedar, and D. R. Green. 1989. Specific inhibition of cell-surface $\mathrm{T}$-cell receptor expression by antisense oligodeoxynucleotides and its effects on the production of an antigen-specific regulatory T-cell factor. Proc. Natl. Acad. Sci. USA. 86:3758-3762.

24. Marcus-Sekura, C. J. 1988. Techniques for using antisense oligodeoxyribonucleotides to study gene expression. Anal. Biochem. 172:289-295.

25. Loke, S. L., C. A. Stein, X. H. Zhang, K. Mori, M. Nakanishi, C. Subasinghe, J. S. Cohen, and L. M. Neckers. 1989. Characterization of oligonucleotide transport into living cells. Proc. Natl. Acad. Sci. USA. 86:3474-3478.

26. Sambrook, J., E. F. Fritsch, and T. Maniatis. 1989. Molecular Cloning: A Laboratory Manual. Cold Spring Harbor Laboratory, Cold Spring Harbor, NY. p. 117.

27. Walder, R. Y., and J. A. Walder. 1988. Role of Rnase H in hybrid-arrested translation by antisense oligonucleotides. Proc. Natl. Acad. Sci. USA. 85:50115015 .

28. Boiziau, C., R. Kurfurst, C. Cazenave, V. Roig, N. T. Thuong, and J.-J. Toulme. 1991. Inhibition of translation initiation by antisense oligonucleotides via an RNase-H independent mechanism. Nucleic Acids Res. 19:1113-1119.

29. Lee, J. C., D. E. Griswold, B. Votta, and N. Hanna. 1988. Inhibition of monocyte IL-1 production by the anti-inflammatory compound, SK\&F 86002 . Int. J. Immunopharmacol. 10:835-843.

30. Smith, D. M., J. A. Johnson, R. Loeser, and R. A. Turner. 1990. Evaluation of tenidap (CP-66,248) on human neutrophil arachidonic acid metabolism, 
chemotactic potential and clinical efficacy in the treatment of rheumatoid arthritis. Agents Actions. 31:102-109.

31. Carty, T. J., A. Marfat, and H. Masamune. 1988. Modification of arachidonic acid metabolism in the treatment of rheumatoid arthritis. Annu. Rep. Med. Chem. 23:181-190.

32. Dower, S. K., J. M. Wignall, K. Schooley, C. J. McMahan, J. L. Jackson, K. S. Prickett, S. Lupton, D. Cosman, and J. E. Sims. 1990. Retention of ligand binding activity by the extracellular domain of the IL-1 receptor. J. Immunol. 142:4314-4320.

33. Palaszynski, E. W. 1987. Synthetic C-terminal peptide of IL-1 functions as a binding domain as well as an antagonist for the IL-1 receptor. Biochem. Biophys. Res. Commun. 147:204-211.

34. Eisenberg, S. P., R. J. Evans, W. P. Arend, E. Verderber, M. T. Brewer, C. H. Hannum, and R. C. Thompson. 1990. Primary structure and functional expression from complementary DNA of a human interleukin-1 receptor antagonist. Nature (Lond.). 343:341-346.
35. Carter, D. B., M. R. Deibel, Jr., C. J. Dunn, C.-S. C. Tomich, A. L. Laborde, J. L. Slighton, A. E. Berger, M. J. Bienkowski, F. F. Sun, R. N. McEwan, et al. 1990. Purification, cloning, expression and biological characterization of an interleukin-1 receptor antagonist protein. Nature (Lond.). 344:633-638.

36. Forsyth, K. D., and R. J. Levinsky. 1989. Role of the LFA-1 adhesion glycoprotein in neutrophil adhesion to endothelium and plastic surfaces. Clin. Exp. Immunol. 75:265-268.

37. Luscinskas, F. W., M. I. Cybulsky, J. M. Kiely, C. S. Peckins, V. M. Davis, and M. A. Gimbrone, Jr. 1991. Cytokine-activated human endothelial monolayers support enhanced neutrophil transmigration via a mechanism involving both endothelial-leukocyte adhesion molecule-1 and intercellular adhesion molecule-1. J. Immunol. 146:1617-1625.

38. Rhyne, J. A. S. B. Mizel, R. G. Taylor, M. Chedid, and C. E. McCall. 1988. Characterization of the human interleukin I receptor on human polymorphonuclear leukocytes. Clin. Immunol. Immunopathol. 48:354-361.

39. Zon, G. 1989. Oligodeoxynucleotides, Antisense Inhibitors of Gene Expression. J. S. Cohen, editor. CRC Press, Boca Raton, FL. pp. 233-247. 